\title{
An Empirical Examination of Relationship between Pareto Principle and Stages of Leadership at University Level
}

\author{
Ayaz Muhammad Khan* \\ Amna Ramzan** \\ Uzma Quraishi***
}

\begin{abstract}
The leading purpose of the current paper was to explore the relationship between Pareto Principle and stages of Leadership Proposed by inordinate leadership expert J.C Maxwell. Through a multistage sampling technique, $(\mathrm{N}=213)$ dyads were chosen to support this empirical evidence to the theory. The paradigm of the study was positivism; quantitative method and survey design were used to collect data through two structured questionnaires Leadership level assessment questionnaire (for subordinates) and Pareto Principle questionnaire (for leaders). It was hypothesized that there was no significant relationship between the Pareto Principle and five levels of leadership proposed by Maxwell. The results of the current paper signposted that, "there was a significant relationship between the Pareto Principle and Five levels of leadership" Proposed by J.C. Maxwell. All the five stages were significantly correlated with the coefficient Pinnacle ( $\mathrm{r}=.46)$, People Development $(\mathrm{r}=.37)$, Production $(\mathrm{r}=.41)$, Permission $(\mathrm{r}=.42)$, and Position $(\mathrm{r}=.46)$. Additional findings were reconnoitred that, People development level has literature support having relationship Pareto Principle with five levels of leadership.
\end{abstract}

Keywords: pinnacle, people development, production, permission, position

\footnotetext{
* Associate Professor, University of Education Lower Mall Campus Lahore Pakistan, Email: ayaz@ue.edu.pk

${ }^{* *} \mathrm{PhD}$ (Education) scholar University of Education Lower Mall Campus Lahore, Email: amnaramzan70@gmail.com

${ }^{* * *}$ Professor, Department of Education, Lahore College for Women University, Lahore
} 


\section{Introduction}

The Pareto Principle, a thought-provoking construct in business and Professional research. It articulates that as a rule $80 \%$ of the impacts or results instigated by just $20 \%$ of the sources or causes. The concept of Pareto Principle was naked by an Italian Economist Vilfredo Pareto in 1897 (Koch, 2013; Reh, 2016). The term Pareto Principle specified by many appellations i.e. 80/20 rules, Pareto Law, Principle of imbalance but in the arena of research was signposted by the Pareto Principle (Wiesenfelder, 2013).

Throughout the Maxwell leadership work, we found this term as Pareto principle or 20/80 principle. Pareto's Principle states that if leadership efforts on the top $20 \%$ most important items they have an $80 \%$ chance of success. John C. Maxwell's " $17^{\text {th }}$ Irrefutable Law of Leadership" The Law of Priorities aligns with this principle. Leaders that priorities are continually thinking ahead and never advance to the point where they no longer need to priorities (Borner, 2012).

Koch (2015) in his book "80/20 managers ten ways to become great leaders "Contests the claim that, the manager achieve abundant more with less effort who use Pareto principle in their daily jobs and become prodigious leaders. The idea of 80/20 rule to up the level of leadership first introduced by Maxwell in 1997 in his book "Becoming a Person of Influence" in which the Maxwell write and denote the notion of 80/20 rules. In the same year, he also concedes this supposition in another book "The Success Journey, the Process of Living Your Dreams" published on February 1997 and argue (Koch, 2011a, 2011b, 2013) that there is a lot of ways to prioritize your tasks keeping in mind your $20 \%$ of your strengths that make excellent work. You could use the $80 / 20$ rule. Give 80 percent of your effort to the top 20 percent (most important) activities. Another way is to focus on exceptional opportunities that promise a huge return. It comes down to this: give your attention to the areas that bear fruit. (Maxwell, 1993).

Passing a year he Gives an account of the same concept in the capsule of the book "Five Levels of Leadership Proven Steps to Maximize your" and "The 21 irrefutable laws of leadership: Follow them and people will follow you" In the research biosphere, the 80/20 rule is truly called the Pareto Principle or the Principle of Factor Sparsity (Edwards, 2015). Richard Koch (2015) Pareto Principle postulate that there are a "few really 
important reasons that explain superior educational performance" and that 80/20 approaches and methods will substantiate brilliant consequences. Educationists can isolate the explanations and slants, and then multiply their occurrence. By using Pareto Principle in education leaders can be talented to brand terrific progress.

The university-level considered the highest level of education in Pakistan. The university-level Leadership permitted to manage their man, money and material resources autonomously. The top-level leaders are fully pontificated to develop their subordinate's leadership abilities (Anwar, Yousuf, \& Sarwar, 2011). Every organization's long-term success emphatically correlated with its capacity to construct viable and dynamic leaders. Numerous senior administrators recognize that there is an absence of formal procedures for growing new and current leaders who have the proper abilities, aptitudes, and viewpoints expected to accept places of initiative (Chu, 2009; Covey, 1989; Moss, 2014). The organization must have the capacity to give a situation in which future and current leader figure out how to adequately lead and do the missions of their organizations. There is the scarcity of literature on this research it is maybe the first one study in this field, where the relationship between Pareto principle and the level of leadership success was explored. Pareto Principle and its effects on leadership success have explored the effect to establish which of the level is the most affected by $80 / 20$ principle in return helping the leadership to achieve a higher level of success proposed by $\mathbf{J}$ C Maxwell.

The present paper provides empirical support to the assumption of Maxwell, that the uses of the 80/20 principle (law of priority) increase your level of leadership. Research on leadership indicates that $50-75 \%$ of organizations are currently managed by people who greatly lacking in leadership competence. They hired or promoted based on technical competence, business knowledge and politics not on leadership skill (Swaroop \& Prasad, 2013).

\section{Objectives of the Study}

For resolving the above debate of the literature the objectives of the current paper were to:

1. Explore the relationship between the Pareto Principle and Maxwell's levels of leadership 
2. Scrutinize the relationship between Pareto Principle and:
i. Position level
ii. Permission level
iii. Production level
iv. People Development level
v. Pinnacle level

\section{Hypotheses}

To what extent of association exist among or between the Pareto Principle and leadership levels at university level it was hypothesized or to test above stated objectives following hypothesis were framed.

$\mathrm{H}_{\mathrm{ol}}$ : There is no significant relationship between the mean score of Pareto Principle and Maxwell's levels of leadership at University level

$\mathrm{H}_{03}$ : There is no significant relationship between the mean score of the Pareto Principle and Maxwell's (positional) level of leadership

$\mathrm{H}_{03}$ : There is no significant relationship between the mean score of the Pareto Principle and Maxwell's (Permission) level of leadership

$\mathrm{H}_{03}$ : There is no significant relationship between the mean score of the Pareto Principle and Maxwell's (Production) level of leadership

$\mathrm{H}_{03}$ : There is no significant relationship between the mean score of the Pareto Principle and Maxwell's (People Development) level of leadership

$\mathrm{H}_{\mathrm{o6}}$ : There is no significant relationship between the mean score of the Pareto Principle and Maxwell's (Personhood) level of leadership

\section{Review of the Related Literature}

The Pareto Principle must use by astute smart people in their day to day life by each organization, by each social assemblage and in all type of society. It can enable people and assemblies to accomplish a great deal more, with significantly less exertion. The 80/20 Principle can raise individual viability and joy. It can duplicate the productivity of partnerships and the adequacy of any association. It even holds the way to raising the quality and amount of open administrations while cutting their cost.

As a successful leader, if you use Pareto principle at level 4 you will develop leadership around you in the same scenario the practice of 80/20 also sets up success for level 5 "Pinnacle". Leaders having special 
potential, contribute the highest rate of return on your investment or production. Pareto Rules also have the utmost of turning around \& rising up leadership around you, emphasize on level "pinnacle". As successor, develop your top 20\% talented leaders. (Maxwell, 1998) the great leadership development expert's "Five Levels of Leadership, Proven Steps to Maximize Your Potential" book contests the claim of the Pareto Principle and its effects on the level of leadership success evidently. Later on, in 2004, Maxwell wrote another book "Winning with People" in which proclaims the idea of 80/20 rules very slightly. Maxwell (2005) affirmed in his book "Thinking for Change" published on July 1, 2005, every leader should use Pareto Principle in deciding priorities in working matters to get the maximum return. By paying attention to the top $80 \%$, exceptional opportunities promise you a huge return. The 80/20 focuses abetted you identify areas that bear fruit. On October 2005 Maxwell published a spectacular book "Developing Leadership Around you" and "Developing Leadership within you" in another book "Today Matters 12 Daily Practices to Guarantee Tomorrow's Success" published on November 8, 2005, Maxwell's notable book in which he described the history of Pareto Principle that goes back to Vilfredo Pareto. Maxwell (2005) advocate that he wanted to improve his leadership capacity so, he learns about the Pareto Principle proposed by economist Vilfredo Pareto, which he did learn in college subject in business degree. "I realized that I needed to focus 80 percent of my time, energy, and resources on my areas of strength, not on counselling and administration". Maxwell (2005) acknowledged I my financial matters always settled by using 80/20 Principle.

Pareto Principle and its effects on Leadership success the supported notion of the current research predicted much time in four books by Maxwell in the year 2007." Up your Business", Be All You Can Be", The Maxwell Daily Reader: 365 Days of Insight to Develop the Leader Within You and Influence Those Around You" and "The 21 Irrefutable Laws of Leadership: Follow Them and People Will Follow You".

Maxwell (2007) Pareto Principle and 80/20 are synonyms. Pareto principle stipulates $80 \%$ work always done by $20 \%$ people in the organization. At every workplace $20 \%$ exceptional people then others they substantially more valuable and effective they should be a reward, equip, empower, motivated and encourage because they are producing $80 \%$ 
outcome. Leaders should fashion $80 \%$ appreciation, cost and support for top $20 \%$ people. Writing in "Be All You Can Be" Maxwell review that, Geniuses people pay $10 \%$ their potential but if $10 \%$ of potential to using $20 \%$ they could double outcomes and motionless have 80 percent of potential unexploited (Maxwell, 2007). Maxwell (2007) confesses that in the process of Developing Leadership he used inspector rule named Pareto Principle. He recommends you should focus on the top $20 \%$ activities that give you $80 \%$ in return. Try to use Pareto Analysis for maintaining to do a list of your activities. By this analysis, you will focus on the $2 \%$ important tasks of your duties. It will be effective for people development and personal development as well.

"Leaders Who Attract Followers they develop the Bottom 20

Percent, Leaders Who Develop Leaders they develop the Top 20

Percent"

Since I learn about Pareto Principle also called 80/20 rules using in prioritizing my life." Every leader needs to understand the Pareto Principle in the area of people oversight and leadership". Overall $20 \%$ people in the firm responsible for $80 \%$ of the success of the company. First, recognize your $80 \%$ producers spent $80 \%$ "people time" on exceptional 20\%. "Regulate what 20 percent of the work gives 80 percent of the return and train an assistant to do the 80 percent less effective work. This "frees up" the producer to do what he/she does best" and requests the top 20\% to do on-the-job preparation for the next $20 \%$ "( Maxwell, 2011).

Maxwell (2014) exhorts in his book "Good Leaders Ask Great Questions" Everyone needs time and support in your organization, it is also impossible for a leader to help everybody personally. As a leader, you should be kind \& supportive for everybody, remind that you must pick/choose the $20 \%$ exceptional people whom you will cultivate. By using Pareto principle If you develop top $20 \%$ leaders of your team with the highest potential and greatest skills, then they will assist and support you in developing the remaining $80 \%$ people. Overall the literature of Maxwell (Maxwell, 1993; Maxwell, 1997; Maxwell, 2001, 2002a, 2002b; Maxwell, 2004; Maxwell, 2007a, 2007b, 2008, 2010a, 2010b, 2011a, 2011b; J.C. Maxwell, 2012; John C Maxwell, 2012a, 2012b; Maxwell, 2013a, 2013b; Maxwell, 2014a, 2014b, 2016; Maxwell \& Dornan, 1997, 2013; Maxwell \& Parrott, 2005) is tested by this study regarding the use of Pareto Principle and Levels of leadership success. 


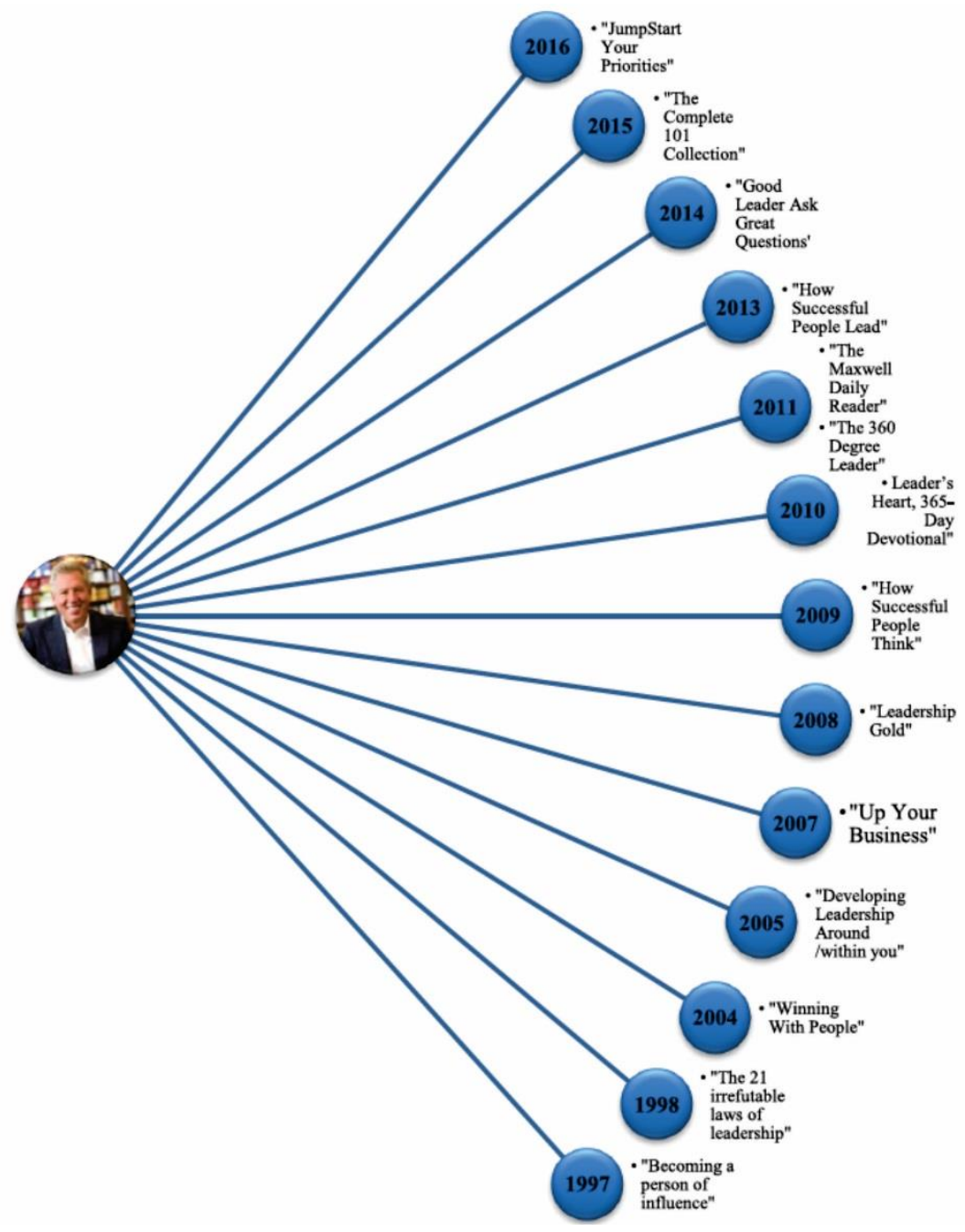

Figure: 1 Maxwell's books discussed Pareto Principle with leadership

\section{Methodology}

The present paper proposed to figure out the existing relationship between the Pareto Principle and five levels of leadership proposed by J.C Maxwell. Nature of the study was quantitative and descriptive survey method was used to collect data from the sample. Data was collect at one point at a time hence the nature of data was cross-sectional and correlation analysis was suited to interpret the collected data (Fraenkel \& Wallen, 
2003; L. Gay, Mills, \& Airasian, 2012; L. R. Gay, Mills, \& Airasian, 2011).

As per the data retrieved from the HEC Site, there was total (51) recognized universities in Punjab. According to HEC (2015) $5^{\text {th }}$ ranking list (Universities/Degree Awarding Institutions (DAIs) of universities recognized and attested by the Higher Education Commission, Islamabad. In Puniab, there were (27) public and (24) private Universities/Degree Awarding Institutions (DAIs). According to the prearranged facts and figure, there were only (10) public and (19) private universities located in the Lahore District. There were only three public universities and nine private universities (in the case of private universities three conditions $*^{*}$ ) of Lahore district in which the education department was working. 230 teachers and their respective leaders were selected through a multistage sampling technique and the questionnaire was circulated among selected dyads. In the existing study, the leaders (Principle, Directors, Chairman, Head of Departments and other supervisory staff) and subordinate (Lecturer, Assistant Professors. Associate Professors and professor) were nominated to evaluate the relationship between Pareto Principle and levels of leadership.

Table 1

The Sample for the Present Study

\begin{tabular}{|c|c|c|}
\hline \multicolumn{2}{|c|}{ Universities Located in Lahore } & Department/s \\
\hline \multirow{3}{*}{$\frac{0}{2}$} & \multirow{3}{*}{$\begin{array}{l}\text { University of Education, Lahore } \\
\text { University of the Punjab, Lahore } \\
\text { Lahore College for Women } \\
\text { University, Lahore }\end{array}$} & Division of Edu. \& LMC, BRC, TC \\
\hline & & Institute of Education \& Research \\
\hline & & Institute of Education \\
\hline \multirow{3}{*}{ 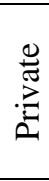 } & \multirow{3}{*}{$\begin{array}{l}\text { University of Management \& } \\
\text { Technology, Lahore } \\
\text { University of Lahore, Lahore } \\
\text { Beacon house National } \\
\text { University, Lahore }\end{array}$} & Arts \& Social Sciences \\
\hline & & Arts \& Social Sciences \\
\hline & & Education \\
\hline
\end{tabular}

Sources:http://hec.gov.pk/english/services/universities/Pak-Us-stcp/

Documents/ Private-Universities-eligible-for-Public-Funding.pdf

${ }^{1}$ Private $\left({ }^{1}\right.$ Education department with Regular Faculty, ${ }^{2}$ not include in the HEC list of given Charter after 30th June 2010 \& ${ }^{3}$ include in HEC list of universities declared eligible for funding under public- privatepartnership Program) universities hold Education Department in Lahore District 


\section{Research Instruments}

The present study was probed by two instruments. To what extent the Pareto Principle was used by university-level leadership was measured by a self-developed questionnaire. The Pareto Principle questionnaire was tested and validated by the researchers. Instrument PPQ has good validity as measured by two experts having more than five years of leadership experience and the Cronbach's Alpha of Pareto Principle Questionnaire was .94. To consider the five levels of leadership an adapted questionnaire Leadership Level Assessment Questionnaire developed by J.C. Maxwell. The Leadership Level Assessment Questionnaire was partially used by the researcher with the acknowledgement of its real author J.C Maxwell.

Table 2

Instruments for Measuring Key Variables

\begin{tabular}{|c|c|c|}
\hline Variable & Instrument \& Factors & No. of Items \\
\hline \multicolumn{3}{|c|}{ he Questionnaire I (LLAQ For Teachers) } \\
\hline 1. Leadership & 1. Level1 Position & 1.1 to 1.3 \\
\hline Levels & 2. Level 2 Permission & 1.4 to 1.8 \\
\hline Questionnaire & 3. Level 3 Production & 13 \\
\hline & 4. Level 4 People Development & 1.14 to 1.17 \\
\hline \multirow{4}{*}{ 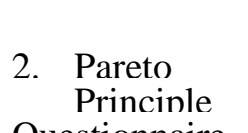 } & \multirow{2}{*}{\multicolumn{2}{|c|}{ Questionnaire II (PPQ For Leadership) }} \\
\hline & & \\
\hline & 1. Prioritization, the Irrefutable law & 1.1 to 1.7 \\
\hline & $\begin{array}{l}\text { of leadership } \\
\text { 2. } 80 / 20 \text { Analysis }\end{array}$ & 2.1 \\
\hline & 3. $80 / 20$ Thinking & 3.1 to 3.12 \\
\hline & 4. Using the $80 / 20$ Rules to be a & \\
\hline & 5. Four Quadrants Matrix & 5.1 to 5.12 \\
\hline
\end{tabular}

\section{Data Analysis}

The purpose of the successive section of the research report is to numerically explore the relationship of Pareto Principle with the level of leadership. This part of the paper shows the quantitative evidence related to data. It starts with cleaning and screening of data which is the initial requirement of any statistical analysis of data then, analysis of descriptive statistics and correlation was calculated to test the hypothesis. The collected data was interpreted by using a variety of statistical techniques 21 version of Statistical Package for Social Sciences (SPSS-21) used for Data Analysis and 18 version of Analysis of Moment Structure (AMOS18) used for Structural Equation Modeling.

Data were tested and screened for assumptions before smearing SEM analysis such as Outliers, Normality, Linearity, homogeneity and uncorrelated error. Dataset was tested for upper and lower values of Quartiles to ascertain 
outliers. It was tested that data was free from outliers and organized for further analysis.

Table 3

Tests of Normality

\begin{tabular}{lcccccc}
\hline & \multicolumn{3}{c}{ Kolmogorov-Smirnov $^{\mathrm{a}}$} & \multicolumn{3}{c}{ Shapiro-Wilk } \\
\cline { 2 - 6 } & Statistic & Df & Sig. & Statistic & df & Sig. \\
\hline Data Normality & .024 & 213 & $.200^{*}$ & .995 & 213 & .779 \\
\hline
\end{tabular}

Normality of data was a prerequisite for SEM analysis by keeping in view normality test was applied. The Shapiro-Wilks test was conducted (p>.05) and it was affirmed that there normal Q-Q plots; Histograms and box plot exhibited normal data set. The more about the indemnity about the normality of data Kolmogorov-Smirnov ( $>$ >.05) was applied. Both tests of normality showed that the value is greater the .05 which signposts the data was normally distributed. In the above table test of normality was exposed and the calculated values assess the normality of the distribution of scores of (Pareto Principle Questionnaire and Leadership Level Assessment Questionnaire). It was supported by Literature a nonSignificant (P>.05) values signposts normality of data (Pallant, J. 2007).

The scatter plot of the independent variable with the dependent variable was around the slope which exposed the linearity of data was and all variables were positively correlated. Preceding executing the SEM the suspicion of the uncorrelated blunder terms was checked. The plot of residuals affirmed that there was no confirmation found of infringement of the suspicion. Watched covariance was discovered genuine that affirms the presumption of Non-spurious relationship. Homogeneity of the specimen socioeconomics was surveyed through t-test $(p>0.5)$ which affirmed the homogeneity of the information with understudy's same foundation of the times of study. Prior to executing SEM homogeneity of the sample was measured by applying t-test and results established that the dyads data was based on homogeneity and all dyads were possessed the same background regarding gender and sector

Table 4

Sector and Gender Wise Distribution of Dyads $(N=213)$

\begin{tabular}{llcccc}
\hline$\#$ & Demographics & Total & Percentage & Mean & SD \\
\hline 1 & Public & 132 & $62.0 \%$ & 1.38 & .48 \\
2 & Private & 81 & $38.0 \%$ & & \\
3 & Male & 114 & $53.5 \%$ & 1.46 & .50 \\
4 & Female & 99 & $46.5 \%$ & & \\
\hline
\end{tabular}


Table 4.1 represents the organizational profile of the respondents among $\mathrm{n}=213(\mathrm{M}=1.38$ \& $\mathrm{SD}=.48)$ respondents 132 (62.0\%) were belonged to public sector and reaming $81(38.0 \%)$ respondents were fell in private category. Further, it also displays the gender wise distribution of the respondents. Gender wise distribution of the $n=213(\mathrm{M}=1.46 \&$ $\mathrm{SD}=.500)$ respondents $114(53.5 \%)$ male and $99(46.5 \%)$ females fit in the sample from which data is collected and finalize for analysis and interpretation.

Table 5

Descriptive Statistics for Independent variable Pareto Principle (N=213)

\begin{tabular}{lcccc}
\hline \multicolumn{1}{c}{ Key Factors of PPQ } & Mini & Maxi & Mean & SD \\
\hline 1 Prioritization & 20.00 & 42.00 & 34.59 & 4.64 \\
2 80/20 Analysis & 18.00 & 42.00 & 31.46 & 5.01 \\
3 80/20 Thinking & 36.00 & 72.00 & 54.95 & 8.47 \\
4 Michael Edwards Constructs & 32.00 & 84.00 & 58.80 & 11.02 \\
5 Four Quadrants Matrix & 29.00 & 72.00 & 52.30 & 9.94 \\
6 Pareto Principle Questionnaire & 157.00 & 312.00 & 232.13 & 32.09 \\
\hline
\end{tabular}

Table 5 exhibits the descriptive statistics for the independent variable. The descriptive analysis displays Minimum values, Maximum values, Mean, Std. error, Std. deviation and Variance for the Pareto Principle. All the key factors i.e. Prioritization, 80/20 analysis, 80/20 thinking, Edward Michael' constructs, four quadrants matrix were screened in this table.

Table 6

Descriptive Statistics for dependent variable Maxwell's Levels of leadership $(N=213)$

\begin{tabular}{lcccc}
\hline \multicolumn{1}{c}{ Key Factors of LLAQ } & Mini & Maxi & Mean & SD \\
\hline 1 Position Leadership Level one & 3.00 & 18.00 & 14.45 & 2.90 \\
2 Permission Leadership Level Two & 11.00 & 30.00 & 23.61 & 3.93 \\
3 Production Leadership Level Three & 13.00 & 30.00 & 23.24 & 3.68 \\
4 People Development Leadership Level Four & 7.00 & 24.00 & 18.12 & 4.27 \\
5 Pinnacle Leadership Level Five & 3.00 & 18.00 & 12.81 & 3.76 \\
6 LLAQ & 52.00 & 115.00 & 92.25 & 12.00 \\
\hline
\end{tabular}


Table 6 parades the descriptive statistics for the dependent variable. The descriptive analysis displays Minimum values, Maximum values, Mean, Std. error, Std. deviation and Variance for (Position, Permission, Production, People Development and Pinnacle) five levels of leadership proposed by Maxwell all the descriptive statistics were screened abovesaid table.

Table 7

The difference in the Sector and Gender-wise with Key Variables $(N=213)$

\begin{tabular}{lccccccc}
\hline & $\begin{array}{c}\text { Levels of } \\
\text { Leadership }\end{array}$ & Variable & Mean & SD & $\begin{array}{c}t- \\
\text { Value }\end{array}$ & $d f$ & Sig \\
\hline Sector & & $\begin{array}{c}\text { Public } \\
\text { Grivate } \\
\text { Gender }\end{array}$ & 1.38 & .48 & 2.74 & 193 & .04 \\
& $\begin{array}{c}\text { Male } \\
\text { Female }\end{array}$ & 1.46 & .50 & 2.82 & 204 & .003 \\
\hline
\end{tabular}

$* p<.05 ; * * p<.001$

An independent sample t-test was conducted to amount significant difference of Pareto Principle with gender and sector. The mean scores of the sector $(p=.04)$ and gender $(p=.003)$ significantly differ with the mean scores of Pareto Principle. The magnitude of difference was also tested by using eta squared, sector (eta squared $=.03 \& .04$ ) in the mean scores of sector and gender respectively.

\section{Correlation Analysis}

Bi-variate Pearson Correlation analysis was accompanied on the Pareto Principle and five levels of leadership to check the initial support for the hypothesized relationship of presented in figure. 2 the initial outputs showed that Pareto Principle and Maxwell's levels of leadership ( $r=.454)$ was significantly correlated. Pareto Principle was also positively correlated with Position, Permission, Production, People Development and Pinnacle with the Coefficient $=.460, .427, .417$ and 368 respectively. Level one (position) and level five (Pinnacle) has the highest coefficient both levels contains $r=.460$. No correlation was calculated among factors and demographic variables of the study. Table 8 and 9 signposts preliminary support for the hypothesized model, additional evidence was discussed in hypothesis testing section of the paper. 
Table 8

Correlation between the Pareto Principle and Maxwell's Levels of Leadership $(N=213)$

\begin{tabular}{lcc}
\hline & Pareto Principle & Levels Of Leadership \\
\hline Pareto Principle & 1 & $.454^{* *}$ \\
Levels Of Leadership & $.454^{* *}$ & 1 \\
\hline **. Correlation is significant at the 0.01 level (2-tailed).
\end{tabular}

Table 9

Correlation between the Pareto Principle and Five Levels of Leadership $(N=213)$

\begin{tabular}{|c|c|c|c|c|c|c|}
\hline Key Variables & $\begin{array}{c}\text { Pareto } \\
\text { Principle }\end{array}$ & Position & Permission & $\begin{array}{l}\text { Produc- } \\
\text { tion }\end{array}$ & $\begin{array}{c}\text { People } \\
\text { Development }\end{array}$ & Pinnacle \\
\hline Pareto Principle & 1 & $.460^{* *}$ & $.427^{* *}$ & $.417^{* *}$ & $.368^{* *}$ & $.461^{* *}$ \\
\hline $\begin{array}{l}\text { Position } 1^{\text {st }} \text { Level of } \\
\text { Leadership }\end{array}$ & & 1 & $.984^{* *}$ & $.958^{* *}$ & $.907^{* * *}$ & $.582^{* *}$ \\
\hline $\begin{array}{l}\text { Permission } 2^{\text {nd }} \text { Level of } \\
\text { Leadership }\end{array}$ & & & 1 & $.972^{* *}$ & $.934^{* *}$ & $.520^{* *}$ \\
\hline $\begin{array}{l}\text { Production } 3^{\text {rd }} \text { Level of } \\
\text { Leadership }\end{array}$ & & & & 1 & $.975^{* *}$ & $.510^{* *}$ \\
\hline $\begin{array}{l}\text { People Development } 4^{\text {th }} \\
\text { Level of Leadership }\end{array}$ & & & & & 1 & $.400^{* * *}$ \\
\hline $\begin{array}{l}\text { Pinnacle } 5^{\text {th }} \text { Level of } \\
\text { Leadership }\end{array}$ & & & & & & 1 \\
\hline
\end{tabular}

Table 10

Baseline Comparisons (Variables)

\begin{tabular}{llllll}
\hline \multirow{2}{*}{ Model } & $\begin{array}{l}\text { NFI } \\
\text { Delta1 }\end{array}$ & $\begin{array}{l}\text { RFI } \\
\text { rho1 }\end{array}$ & $\begin{array}{l}\text { IFI } \\
\text { Delta2 }\end{array}$ & $\begin{array}{l}\text { TLI } \\
\text { rho2 }\end{array}$ & CFI \\
\hline Default model & .949 & & 1.000 & .823 & .928 \\
Saturated model & 1.000 & & 1.000 & & 1.000 \\
Independence model & .000 & .000 & .000 & .000 & .000 \\
\hline
\end{tabular}

Researchers utilized Structural Equation Modeling (SEM) to test the correlation between the Pareto Principle (Independent Variable) and Maxwell's levels of leadership (Dependent Variable/s) using the AMOS18 software. Path analysis was used to study the multi-relationship between or among variables. The model goodness was also tested by using 
SEM. The values of the table no 10 Specifies model is a good fit or not. Multiple good Fit designates NFI=.949, CFI=.928, TLI= .823 and IFI=1.000 which display model was a good fit. The overall summary of model fitness expounded in Table 10.

Table 11

Covariance between Variables ( $N=2-13$ )

\begin{tabular}{cccccccc}
\hline & & & Estimate & S.E. & C.R. & P & Label \\
\hline 115 & $<->$ & 111 & 2.932 & .400 & 7.322 & $* * *$ & par_1 \\
111 & $<-->$ & 114 & 7.282 & .744 & 9.782 & $* * *$ & par_2 \\
111 & $<-->$ & 113 & 9.258 & .919 & 10.075 & $* * *$ & par_3 \\
111 & $<-->$ & 112 & 9.717 & .951 & 10.212 & $* * *$ & par_4 \\
115 & $<-->$ & 112 & 4.354 & .649 & 6.713 & $* * *$ & par_5 \\
114 & $<-->$ & 112 & 12.465 & 1.254 & 9.937 & $* * *$ & par_6 \\
113 & $<-->$ & 112 & 15.607 & 1.538 & 10.147 & $* * *$ & par_7 \\
114 & $<->$ & 113 & 12.732 & 1.253 & 10.165 & $* * *$ & par_8 \\
115 & $<-->$ & 113 & 4.180 & .632 & 6.614 & $* * *$ & par_9 \\
115 & $<->$ & 114 & 2.725 & .504 & 5.408 & $* * *$ & par_10 \\
111 & $<-->$ & PPQ & 35.923 & 5.900 & 6.088 & $* * *$ & par_11 \\
112 & $<-->$ & PPQ & 55.467 & 9.692 & 5.723 & $* * *$ & par_12 \\
113 & $<-->$ & PPQ & 52.883 & 9.444 & 5.600 & $* * *$ & par_13 \\
114 & $<-->$ & PPQ & 38.815 & 7.720 & 5.028 & $* * *$ & par_14 \\
115 & $<-->$ & PPQ & 30.508 & 5.008 & 6.092 & $* * *$ & par_15 \\
\hline
\end{tabular}

On the bases of above-stated table values hypothesis were tested. Additional the path of AMOS-18 output exhibits the coefficients for specific variables. Variances between variables were also tested in table no 12. Level five and level one contains maximum variance. All the values in table no 12 estimates significance, and all variables have good (C.R) composite reliability.

Table 12

Variances between Variables $(N=213)$

\begin{tabular}{cccccc}
\hline & Estimate & S.E. & C.R. & P & Label \\
\hline 115 & 4.277 & .415 & 10.296 & $* * *$ & par_22 \\
111 & 5.938 & .577 & 10.296 & $* * *$ & par_23 \\
114 & 10.852 & 1.054 & 10.296 & $* * *$ & par_24 \\
113 & 15.712 & 1.526 & 10.296 & $* * *$ & par_25 \\
112 & 16.421 & 1.595 & 10.296 & $* * *$ & par_26 \\
PPQ & 1025.476 & 99.603 & 10.296 & $* * *$ & par_27 \\
\hline
\end{tabular}




\section{Hypothesis Testing}

In correlational studies, it was a common assumption that the hypothesis/s was tested on the bases of existing correlation among or between variables. The figure given below AMOS path output designates the correlation between Pareto Principle and five levels of leadership advanced by J.C. Maxwell.

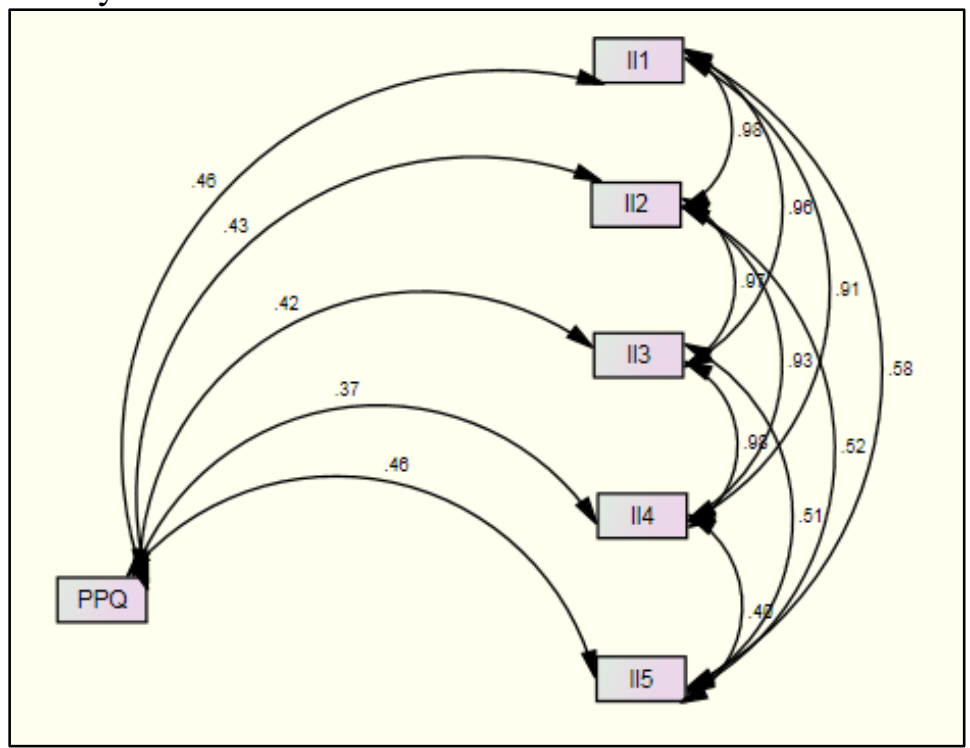

Figure 2: Correlation between the Pareto Principle and levels of leadership

Pareto Principle and Maxwell's levels of leadership

$\mathrm{H}_{\mathrm{ol}}$ : There is no significant relationship between the mean score of the Pareto Principle and Maxwell's levels of leadership at University level. The hypothesis $\mathrm{H}_{\mathrm{o}}$ was rejected at the significance level $\mathrm{p}<.05$ and $\mathrm{r}=.45$ which shows a medium correlation between Pareto Principle and Maxwell's levels of leadership. Cohen (1988) suggests the magnitude of correlation among or between variables that was (small correlation $r=.10$ to .29 , Medium correlation $r=.30$ to .49 and large correlation $r=.50$ to 1.0) (Cohen, Cohen, West, \& Aiken, 1983; Keith, 2014; Pallant, 2005; Wang \& Wang, 2012) the calculated $\mathrm{r}=.45$ indicates medium correlation.

\section{Pareto Principle and Maxwell's $1^{\text {st }}$ level of leadership}

$\mathrm{H}_{\mathrm{o} 2}$ : There is no significant relationship between the mean score of the Pareto Principle and Maxwell's (positional) level of leadership. The hypothesis $\mathrm{H}_{\mathrm{o} 2}$ was rejected at the significance level $\mathrm{p}<.05$ and $\mathrm{r}=$ .46 which shows a medium correlation between Pareto Principle and 
Maxwell's levels of leadership. Cohen (1988) suggests the magnitude of correlation among or between variables that was (small correlation $r=.10$ to .29 , Medium correlation $r=.30$ to .49 and large correlation $r=.50$ to 1.0) (Cohen, et al., 1983; Keith, 2014; Pallant, 2005; Wang \& Wang, 2012) the calculated $r=.46$ indicates medium correlation.

Pareto Principle and Maxwell's $2^{\text {nd }}$ level of leadership

$\mathrm{H}_{03}$ : There is no significant relationship between the mean score of the Pareto Principle and Maxwell's (Permission) level of leadership. The hypothesis $\mathrm{H}_{03}$ was rejected at the significance level $\mathrm{p}<.05$ and $\mathrm{r}=.43$ which shows a medium correlation between Pareto Principle and Maxwell's levels of leadership. Cohen (1988) suggests the magnitude of correlation among or between variables that was (small correlation $r=.10$ to .29 , Medium correlation $r=.30$ to .49 and large correlation $r=.50$ to 1.0) (Cohen, et al., 1983; Keith, 2014; Pallant, 2005; Wang \& Wang, 2012) the calculated $r=.43$ indicates medium correlation.

Pareto Principle and Maxwell's $3^{\text {rd }}$ level of leadership

$\mathrm{H}_{04}$ : There is no significant relationship between the mean score of the Pareto Principle and Maxwell's (Production) level of leadership. The hypothesis $\mathrm{H}_{04}$ was rejected at the significance level $\mathrm{p}<.05$ and $\mathrm{r}=.42$ which shows a medium correlation between Pareto Principle and Maxwell's levels of leadership. Cohen (1988) suggests the magnitude of correlation among or between variables that was (small correlation $r=.10$ to .29 , Medium correlation $r=.30$ to .49 and large correlation $r=.50$ to 1.0) (Cohen, et al., 1983; Keith, 2014; Pallant, 2005; Wang \& Wang, 2012) the calculated $r=.42$ indicates medium correlation.

Pareto Principle and Maxwell's $4^{\text {th }}$ level of leadership

$\mathrm{H}_{05}$ There is no significant relationship between the mean score of Pareto Principle and Maxwell's (People Development) level of leadership. The hypothesis $\mathrm{H}_{05}$ was rejected at the significance level $\mathrm{p}<.05$ and $\mathrm{r}=.37$ which shows a medium correlation between Pareto Principle and Maxwell's levels of leadership. Cohen (1988) suggests the magnitude of correlation among or between variables that was (small correlation $r=.10$ to .29 , Medium correlation $r=.30$ to .49 and large correlation $r=.50$ to 1.0) (Cohen, et al., 1983; Keith, 
2014; Pallant, 2005; Wang \& Wang, 2012) the calculated $r=.37$ indicates medium correlation.

Pareto Principle and Maxwell's $5^{\text {th }}$ level of leadership

$\mathrm{H}_{\mathrm{ob}}$ : There is no significant relationship between the mean score of the Pareto Principle and Maxwell's (Personhood) level of leadership. The hypothesis $\mathrm{H}_{06}$ was rejected at the significance level $\mathrm{p}<.05$ and $\mathrm{r}=.46$ which shows a medium correlation between Pareto Principle and Maxwell's levels of leadership. Cohen (1988) suggests the magnitude of correlation among or between variables that was (small correlation $r=.10$ to .29 , Medium correlation $r=.30$ to .49 and large correlation $r=.50$ to 1.0) (Cohen, et al., 1983; Keith, 2014; Pallant, 2005; Wang \& Wang, 2012) the calculated $r=.46$ indicates medium correlation.

\section{Results and Findings}

The purpose of this paper was to explore the difference between Pareto Principle and levels of leadership proposed by Maxwell. The results of descriptive statistics and SEM were disclosed that the Pareto principle and levels of leadership positively correlated. Further results indicate the Pareto Principle also positively correlated with each specific level of leadership introduced my J.C. Maxwell. The stated six hypotheses were rejected at all the levels of leadership were positively correlated. Maxwell's five levels positively correlated with the coefficient Pinnacle $(\mathrm{r}=.46)$, People Development $(\mathrm{r}=.37)$, Production $(\mathrm{r}=.41)$, Permission $(\mathrm{r}=.42)$, and Position ( $\mathrm{r}=.46)$. Supplementary conclusions were explored that, People development level has literature support having relationship Pareto Principle with five levels of leadership.

\section{Discussion and Future Directions}

As it was supported by literature Pareto Principle and level four were interrelated. The rejection of $5^{\text {th }}$ hypothesis supported the assumption of Maxwell (2011)

Every leader needs to understand the Pareto Principle in the area of people oversight and leadership". Overall $20 \%$ people in the firm responsible for $80 \%$ of the success of the company. First, recognize your $80 \%$ producers spent $80 \%$ "people time" on 
exceptional $20 \%$. "Regulate what 20 percent of the work gives 80 percent of the return and train an assistant to do the 80 percent less effective work. This "frees up" the producer to do what he/she does best" and requests the top 20\% to do on-the-job preparation for the next $20 \%$ "( Maxwell, 2011).

Maxwell also confessed in his wrings that, the production organization also depended on the utilization of the Pareto Principle by their leadership. The rejection of hypothesis affirms the supposition of Maxwell (2007)

Pareto principle stipulates $80 \%$ work always done by $20 \%$ people in the organization.in every workplace $20 \%$ exceptional people than others they substantially more valuable and effective they should be a reward, equip, empower, motivated and encourage because they are producing $80 \%$ outcome. Leaders should fashion $80 \%$ appreciation, cost and support for top $20 \%$ people. Writing in "Be All You Can Be" Maxwell review that, Geniuses people pay $10 \%$ their potential but if $10 \%$ of potential to using $20 \%$ they could double outcomes and motionless have 80 percent of potential unexploited" (Maxwell, 2007).

As Pareto Principle and production level was positively correlated Chu (2009) affirm that the long-term success and production of an organization depends upon the utilization of 80/20 rules by their leadership. Richard Koch (2015) confess that Pareto Principle proposes that there are a "few really important reasons that explain superior educational performance" and that 80/20 approaches and methods will substantiate brilliant consequences. The other hypothesis rejection may cause by contextual alterations as prescribed in literature or other variations of the study. The future studies may be conducted to accept or reject the results of the current paper. It may also be conducted causalcomparative or in another form of research. The leadership level assessment questionnaire was partially used in the present paper it may be used completely in future studies for more precise results. Overall the literature of Maxwell (Maxwell, 1993; Maxwell, 1997; Maxwell, 2001, 2002a, 2002b; Maxwell, 2004; Maxwell, 2007a, 2007b, 2008, 2010a, 2010b, 2011a, 2011b; J.C. Maxwell, 2012; John C Maxwell, 2012a, 2012b; Maxwell, 2013a, 2013b; Maxwell, 2014a, 2014b, 2016; Maxwell \& Dornan, 1997, 2013; Maxwell \& Parrott, 2005) is supported by this study regarding the use of Pareto Principle and Levels of leadership success. 
The future direction of this study may also be embedded across the organization as previous studies in Pakistan acknowledge that the university-level considered highest level of education in Pakistan. The university-level Leadership permitted to manage their man, money and material resources autonomously. The top-level leaders are fully pontificated to develop their subordinate's leadership abilities (Anwar, Yousuf, \& Sarwar, 2011) with relation to the results of present study it may be recommended for university level leadership for the successful usage to Pareto Principle or $80 / 20$ rules in their daily professional dealing which may increase their level of leadership and productivity as well. Other future studies may also be conducted to assess its effects on the organization outcomes the may be more precise empirical support to the assumption of the Maxwell. 


\section{References}

Anwar, M. N., Yousuf, M. I., \& Sarwar, M. (2011). Decision-making practices in universities of Pakistan. Journal of Diversity Management (JDM), 3(4), 19-26.

Borner, P. (2012). Activity is not necessarily accomplishment. Retrieved from http://www.peterborner.com/2012/04/06/activity-is-notnecessarily-accomplishment/

Chu, C. M. (2009). Mentoring for leadership in Pacific education.

Cohen, J., Cohen, P., West, S. G., \& Aiken, L. S. (1983). Applied multiple regression/correlation for the behavioural sciences

Covey, S. (1989). The seven habits of highly effective people: Restoring the character ethic: New York: Simon and Schuster.

Edwards, M. (2015). Using the 80:20 Rule to be a Better Leader. Retrieved from https://www.linkedin.com/pulse/using-8020-rule-better-leadermichael-edwards

Fraenkel, J. R., \& Wallen, N. E. (2003). How to design and evaluate research in education: McGraw-Hill Higher Education.

Gay, L., Mills, G., \& Airasian, P. (2012). Overview of qualitative research. Educational Research: Competencies for Analysis and Applications.

Gay, L. R., Mills, G. E., \& Airasian, P. W. (2011). Educational research: Competencies for analysis and applications: Pearson Higher Ed.

Keith, T. Z. (2014). Multiple regression and beyond: An introduction to multiple regression and structural equation modelling: Routledge.

Koch, R. (2011a). The 80/20 principle: the secret to achieving more with less: Crown Business.

Koch, R. (2011b). Living the 80/20 Way, New Edition: Work Less, Worry Less, Succeed More, Enjoy More: Nicholas Brealey Publishing.

Koch, R. (2013). The 80/20 Manager: Ten ways to become a great leader: Hachette UK.

Maxwell, J. C. (1993). Developing the leader within you: Thomas Nelson Inc.

Maxwell, J. C. (1997). Your Roadmap for Success: T. Nelson.

Maxwell, J. C. (2001). The power of leadership: David C Cook. 
Maxwell, J. C. (2002a). Leadership 101: What every leader needs to know: Thomas Nelson Inc.

Maxwell, J. C. (2002b). Your Road Map for Success: You Can Get There from Here: Thomas Nelson Inc.

Maxwell, J. C. (2004). The Journey from Success to Significance: J. Countryman.

Maxwell, J. C. (2007a). The 21 irrefutable laws of leadership: Follow them and people will follow you: Thomas Nelson Inc.

Maxwell, J. C. (2007b). Failing forward: Harper Collins.

Maxwell, J. C. (2008). Go for gold: Inspiration to increase your leadership impact: Thomas Nelson Inc.

Maxwell, J. C. (2010a). Everyone communicates few connect: What the most effective people do differently: Thomas Nelson Inc.

Maxwell, J. C. (2010b). A Leader's Heart: 365-Day Devotional Journal: Thomas Nelson Inc.

Maxwell, J. C. (2011a). The 360-degree leader with Workbook: Developing Your Influence from Anywhere in the Organization: Thomas Nelson Inc.

Maxwell, J. C. (2011b). The Maxwell daily reader: 365 days of insight to develop the leader within you and influence those around you: Thomas Nelson Inc.

Maxwell, J. C. (2012). The complete 101 collection: What every leader needs to Know: Thomas Nelson Incorporated.

Maxwell, J. C. (2012a). The law of sacrifice: lesson 18 from The 21 Irrefutable Laws of Leadership: Harper Collins.

Maxwell, J. C. (2012b). Mentor 101: What every leader needs to know: Thomas Nelson Inc.

Maxwell, J. C. (2013a). The 17 indisputable laws of teamwork: Embrace them and empower your team: Thomas Nelson Inc.

Maxwell, J. C. (2013b). Be a people person: Effective leadership through effective relationships: David C Cook.

Maxwell, J. C. (2014a). Good leaders ask great questions: Your Foundation for Successful Leadership: Hachette Nashville. 
Maxwell, J. C. (2014b). Thinking for a change: 11 Ways Highly Successful People Approach Life and Work: FaithWords.

Maxwell, J. C. (2016). JumpStart Your Priorities: A 90-Day Improvement Plan: Center Street.

Maxwell, J. C., \& Dornan, J. (1997). Becoming a person of influence: How to positively impact the lives of others: Thomas Nelson Inc.

Maxwell, J. C., \& Dornan, J. (2013). How to influence people: Make a difference in your world: Thomas Nelson Inc.

Maxwell, J. C., \& Parrott, L. (2005). 25 ways to win with people: how to make others feel like a million bucks: Thomas Nelson Inc.

Moss, B. K. (2014). Leadership development in the local church: An intentional strategy for developing leaders at every level: Liberty University.

Pallant, J. (2005). SPSS survival guide. Crow's Nest, NSW: Allen \& Unwin.

Reh, F. J. (2016). Understanding The Pareto's Principle - The 80-20 Rule. Retrieved from https://www.thebalance.com/pareto-s-principle-the80-20-rule-2275148

Swaroop, \& Prasad. (2013). Are Leaders Born or Made? Asia Pacific Journal of Marketing \& Management Review, Vol.2(8), August (2013)( ISSN 2319-2836), 1-6.

Wang, J., \& Wang, X. (2012). Structural equation modelling: Applications using Mplus: John Wiley \& Sons.

Wiesenfelder, H. (2013). Using Pareto Analysis on Surveys. Retrieved from http://www.brighthubpm.com/templates-forms/75631-usingpareto-analysis-on-surveys/

Citation of this Article:

Khan, A. M., Ramzan, A., \& Qureshi, U. (2018). An empirical examination of relationship between Pareto principle and stages of leadership at university level. Pakistan Journal of Education, 35 (3), $119-140$. 